\title{
BRASIL NO SÉCULO XXI NA GEOPOLÍTICA DA CRISE: para onde apontam as utopias?
}

\author{
Alba Maria Pinho de Carvalho \\ Universidade Federal do Ceará (UFC) \\ Eliana Costa Guerra \\ Universidade Federal do Rio Grande do Norte (UFRN)
}

BRASIL NO SÉCULO XXI NA GEOPOLÍTICA DA CRISE: para onde apontam as utopias?

Resumo: Na temporalidade histórica do capital em sua fase de crise estrutural, esse artigo discute a contemporaneidade brasileira, colocando-a no foco da crítica. Parte de uma configuração dos circuitos da geopolítica da crise na civilização do capital no século XXI, como discussão de fundo, a delinear posições e deslocamentos no cenário mundial. Trabalha, como foco analítico, o Brasil do Ajuste que se afirma dominante, em meio aos tensionamentos e lutas democráticas. Nesta perspectiva demarca a inserção do país ao capitalismo financeirizado, circunscrevendo ciclos de ajuste e discutindo políticas assumidas pelo Estado Ajustador, ao longo dos últimos vinte e cinco anos. Adentra no "jogo de xadrez" da crise brasileira, sustentando sua vinculação orgânica aos ciclos de ajuste, a revelar um esgotamento do modelo rentistaextrativista, com mecanismos de distribuição de renda via políticas de enfrentamento à pobreza. Mais especificamente, é o esgotamento do modelo de "crescimento com inclusão", característico dos governos petistas. No contexto da crise e da retomada da ortodoxia das políticas de ajuste, problematiza as lutas e formas de resistência, levantando a questão da pulsação das energias emancipatórias, em tempos de conservadorismo e de captura do Estado por interesses privados, encarnada em poderosos "lobbies". Por fim, conclui com o dilema que perpassa a contemporaneidade brasileira de pensar utopias na perspectiva da emancipação.

Palavras-chave: Geopolítica da crise, contemporaneidade brasileira, ciclos de ajuste, crise, utopias.

BRAZIL IN THE XXI CENTURY GEOPOLITICS CRISIS: where do the utopias point?

Abstract: Set In the historical span of time of capital, at its structural crisis phase, this article discusses the current Brazilian insertion, placing it at the center of a critical evaluation. As part of a configuration including the crisis' geopolitical circuits seen in the capital civilization of the XXI century, it is set as a background discussion that delineates positions and displacements within the world scenario. It evaluates, as its analytic focus, Brazil, as it promotes its economical adjustments that dominate the scene within tensions and democratic struggles. Within this perspective, it demarcates the country's insertion in the finance-dominated capitalism encompassing adjustments cycles, and discuss policies adopted by the State in its accommodating role, seen along the late 25 years. It goes into "the chess game" of the Brazilian crisis by evaluating its organic attachment to the adjustment cycles that reveals the exhaustion of a rent-extract model and its tools of public income distribution to fight poverty. More specifically, it is the exhaustion of a "growing-with-inclusion" model associated to the Workers Party's administration of the economy. Considering the crisis' context and resumption of the orthodoxy of adjustment policies, resisting struggles raise the question of strong emancipating energies at a time of conservatism and attacks to the State by private entrepreneurs rallied in powerful lobbies. Analysis is closed, then, by the difficult choice faced by Brazilian contemporary leaders to propound utopias aimed at an emancipating perspective. Key words: Geopolitical crisis, brazilian contemporary, situation adjustment cycles, crisis, utopias. 


\section{INTRODUÇÃO}

A temática em foco circunscreve uma abordagem fundante no âmbito da discussão acerca de experiências, expressões e espaços de utopia na cena contemporânea brasileira. ${ }^{1}$ De fato, (re)pensar utopias, neste início do século XXI, impõe-se como uma necessidade histórica, a exigir um esforço específico e peculiar, no sentido de antever o ainda não de Ernest Bloch $(1974)^{2}$, que já desponta no presente, sob a forma de indicações, pistas, sinais, traços de possibilidades, a guardar potencialidades, a desenvolver-se em configurações politicas contemporâneas ${ }^{3}$.

Para tanto, precisamos ampliar nosso olhar sobre o presente, buscando desvendar o existente, o que está posto, focando as suas múltiplas dimensões constitutivas, ao adentrar no que é invisibilizado, no âmbito do pensamento dominante, a circular nos diferentes espaços da vida social ${ }^{4}$.

Assim, tomamos, como foco analítico, a contemporaneidade brasileira, ou seja, o Brasil no século XXI, nos seus ciclos e tramas, a nos interpelar ao exercício do pensar crítico. É o presente como desafio de estudos e investigações. Desvendálo pressupõe desvelar o cenário da civilização do capital, nos circuitos do que denominamos geopolítica da crise, que marca, decisivamente, o tempo histórico presente.

De fato, a civilização contemporânea do capital encarna as expressões de uma crise estrutural ${ }^{5}$ : o capitalismo financeirizado não cresce, produzindo déficits e dívidas que se alastram pelos meandros do sistema; políticas de ajuste a impingir pesados ônus às nações, em suas imposições de austeridade; classes trabalhadoras vivenciando a precarização estrutural do trabalho e a condição de proletariedade (ALVES, 2008). Analistas sustentam que o capitalismo parece estruturalmente atingido por uma overdose de si mesmo, na condição de um sistema que se decompõe, sem a contribuição de qualquer inimigo estruturalmente designado para abatê-lo (ARANTES, 2015). Avaliações apontam para o esgotamento da civilização capitalista, sem saídas à vista (GRZYBOWSKI, 2015). No entanto, em meio a um avanço da agenda conservadora, em tempos de crise e ajustes, pulsam energias emancipatórias, a encarnar formas de resistência e tensionamentos com o sistema do capital. E, a luta por direitos afirma-se como uma trincheira privilegiada da luta de classes na contemporaneidade (ARANTES, 2015).

Para desvendar esse enigma Brasil, nos circuitos do sistema do capital em crise, empreendemos, neste artigo, um duplo movimento analítico: proceder a um esboço das grandes linhas que configuram o cenário geopolítico do capitalismo em crise, tentando apreender a dinâmica contraditória que preside o reordenamento das relações de poder em escala global, repercutindo, de modo particular, no contexto brasileiro; demarcar as especificidades da contemporaneidade brasileira nos seus ciclos históricos. Guiadas por estas análises, ousamos problematizar os sentidos da utopia que parecem germinar no árido solo da civilização do capital, em terra Brasilis.

\section{DELINEAMENTOS DOCENÁRIO GEOPOLITICO DO CAPITALISMO EM CRISE}

Lançando um olhar crítico sobre esta civilização do capital no Século XXI, constatamos um reordenamento das relações de poder, com deslocamentos, reconfigurações e impasses entre nações e blocos políticos, seguindo os movimentos incessantes da História, com mudanças e alterações em ritmo intenso. Vivenciamos tempos de transição (SANTOS, 2004, 2006), com a sensação de que "[...] tudo que parece sólido desmancha-se no ar.", parafraseando Marx e Engels (1998) ao referirse à segunda metade do século XIX. Assim, configuram-se movimentações, articulações, nos circuitos de hegemonia e de domínio do capitalismo contemporâneo. Trata-se dos delineamentos de uma nova geopolítica a esboçar-se neste início de século: a geopolítica da crise.

De forma inconteste, no cenário geopolítico do sistema do capital, desenham-se expressões de confronto com o domínio imperialista instituído no Ocidente, nas últimas décadas do século $X X^{6}$. Temse, em curso, um reordenamento das relações de poder a exigir avaliações da geopolítica mundial no século XXI, a partir de uma ampliação dos parâmetros de análise da correlação de forças, no capitalismo contemporâneo. Nesta perspectiva, cabe circunscrever dois fenômenos-chave que marcam este jovem século XXI: os ataques de 11 de setembro de 2001, como tragédia justificadora de qualquer ofensiva em nome de proteger a nação norte-americana; e a crise financeira do capital, emergente em 2008 e em curso, a farsa, resultante do modo de funcionamento do sistema e apresentada como imprevisível, a atingir os mercados, justificando quaisquer medidas para salvaguardar os mercados financeiros (ZIZEK, 2011) ${ }^{7}$.

A estes dois marcos históricos fundantes, circunscritos na primeira década do século $X X I$, agregam-se fenômenos sócio-políticos e culturais que, na segunda década do século, em curso, estão a desencadear mudanças no cenário mundial, com deslocamentos e reconfigurações geopolíticas: rebeliões e grandes manifestações, a gestarem movimentos transnacionais, sendo emblemáticos a Primavera Árabe, o Ocupay Wall Street, os Indignados, as mobilizações urbanas no Brasil, com o Movimento Passe Livre e as manifestações que tomaram as ruas do País, em 2013. Em diferentes partes do mundo, sobremaneira, em alguns países da Europa e do mundo árabe, 
conflitos e o agravamento do desemprego, levaram centenas de jovens a ocupar as ruas e reivindicar liberdades democráticas e melhores condições de vida e de trabalho, mas geraram, ao mesmo tempo, solo fértil para a disseminação e implantação de jihadistas e o fortalecimento do Exercito Islâmico, além de deslocamentos de populações, em busca da terra prometida ${ }^{8}$, com centenas de refugiados e clandestinos, fugitivos das guerras e perseguições e das situações de penúria. Neste contexto de acirramento, os jovens do Estado Islâmico entendem que podem matar ou morrer para erradicar obstáculos e restaurar a Lei de Deus na terra e defender os muçulmanos. Os atentados na Europa, particularmente em Paris, em 2015, no início do ano e em novembro passado, constituem exemplos emblemáticos do crescimento do fundamentalismo religioso, uma das facetas do esgarçamento do tecido social, em tempos de crise.

A rigor, este contexto demarca uma nova "[...] temporalidade histórica do capital, em sua fase de crise estrutural." (ALVES, 2015, p. 3), com deslocamentos de posições nas intricadas tramas das relações de poder. Na primeira década do século XXI, reconfigura-se a posição dos EUA como potência hegemônica no sistema do capital, em meio ao declínio do seu poder econômico-financeiro e à consolidação da sua posição como potência militar, na guerra permanente ao terror, desmontando o mito da democracia estadunidense. Nos circuitos da crise do capital, é também patente o declínio da União Europeia, enquanto a China, nesse período, afirma-se como potência no capitalismo contemporâneo, materializando sua presença comercial, inclusive como alternativa para a América Latina, no enfrentamento à crise do capital. De fato, o início do século XXI revela a China como uma economia capitalista das mais selvagens da História. A civilização do capital em crise é, então, surpreendida com o espetacular desempenho da economia chinesa, com taxa média de crescimento, até 2010 , em torno de $10 \%$.

No entanto, a crise do capital também é chinesa. E, em meados da segunda década do século XXI, a China está a trilhar o caminho da crise, vivenciando a sua primeira crise capitalista macroeconômica. A partir de 2010, a economia chinesa sofre uma desaceleração de $35 \%$ e, em 2014, registra a mais baixa taxa de crescimento, desde 1991. Assim, o capitalismo chinês mostra sua verdadeira face, com graves distorções estruturais nos setores imobiliário e financeiro. A crise chinesa repercute na civilização contemporânea do capital, atingindo, de modo particular, o modelo de ajuste de países latino-americanos, que assumem o extrativismo como uma alternativa de inserção dependente no capitalismo globalizado, em especial, o Brasil. E, segundo analistas, é possível que a crise na China esteja apenas a começar! (NADAL, 2015; BELLUZZO, 2015; FIORI, 2007).
Uma marca decisiva no cenário geopolítico, no início do século XXI - que se revela, sobremodo, na primeira década - é a crise expansiva do Império Americano, observando-se uma diminuição da capacidade de intervenção unilateral dos Estados Unidos, que se aprofunda, mesmo nesta primeira metade da segunda década, quando a economia norte-americana esboça uma reação às graves distorções estruturais, decorrentes da crise. Luís Fiori (2007), em suas avaliações, em 2007, abre uma fecunda via para pensar a posição dos EUA nesta geopolítica da crise, delineando uma perspectiva multipolar de análise do domínio mundial. Afirma este analista que a crise do poder unipolar norteamericano está a reacender a competição entre as nações, demarcando o fenômeno contemporâneo da volta das nações, com o aumento dos graus de incerteza e de liberdade de ação das velhas e novas potências, em cada um dos tabuleiros regionais, do sistema mundial (FIORI, 2007).

Assim, no Oriente Médio, na posição de epicentro da conjuntura internacional, encontrase o principal símbolo das limitações do projeto imperial norte-americano, neste tempo histórico do século XXI. O insucesso da intervenção militar, sobretudo, depois do fim da guerra do Iraque corroeu a credibilidade dos EUA como potência bélica, provocando um efeito paradoxal: uma reviravolta na correlação do poder regional, ao fortalecer o eixo de poder Xiita, liderado pelo Irã, que se transformou no grande desafiante da hegemonia norte-americana, no Oriente Médio, exercendo uma influência, cada vez maior, na região. Este aumento da influência iraniana acirrou a competição regional, com Israel, mas também com o Egito, a Arábia Saudita, a Jordânia e pode ter desdobramentos muito complicados, se desencadear uma corrida atômica na região. Incontestavelmente, os EUA seguirão tendo grande influência no Oriente Médio, mas perderam sua posição arbitral. E mais: no atual tempo histórico, terão que conviver com a presença ativa da Rússia, da China e de outros países com interesses nos recursos energéticos da região (FIORI, 2007).

Por sua vez, o bloco constituinte da União Europeia passa por uma ampliação, ao mesmo tempo em que há um aumento de extensão da Organização do Tratado do Atlântico Norte (OTAN), mas o continente europeu, neste jovem século XXI, vive uma situação de paralisia estratégica e decisória. A rigor, a União Europeia, como bloco regional, não dispõe de um poder central unificado e homogêneo, capaz de definir e impor objetivos e prioridades ao conjunto dos Estados associados. Neste cenário de crise e declínio, é indisfarçável o aumento da resistência ao unilateralismo norte-americano e ao poder militar da OTAN (FIORI, 2007).

Já o Leste Asiático configura-se como a região de maior dinamismo econômico dentro do 
sistema mundial, sendo, ao mesmo tempo, o espaço regional onde está em curso a competição, mais intensa e explícita, pela hegemonia, envolvendo velhas potências imperiais, como a China, o Japão e a Coreia, mas, também, a Rússia e os EUA (FIORI, 2007). Em verdade, a disputa é acirrada, consubstanciando o poderio das nações, no âmbito de uma cartografia descentrada, com diferentes polos de domínio, a confrontar com o Império Global norte-americano, do século XX.

No xadrez geopolítico do tempo presente, o tabuleiro regional da América Latina delineia um quadro peculiar: a disputa não se dá entre os países, ou seja, não se efetiva entre os próprios Estados latino-americanos (FIORI, 2007). O confronto encarna-se em uma disputa pela hegemonia entre forças que propugnam a autonomia desta região, com processos de integração soberanos e forças conservadoras, vinculadas aos interesses do grande capital e alinhadas aos EUA. Essa disputa hegemônica assume configurações distintas entre a primeira década do século XXI, com uma virada à esquerda e a década em curso, com tendência assustadora de fortalecimento e expressão das forças conservadoras e de direita.

Nesta cartografia geopolítica do século XXI, no contexto do capitalismo contemporâneo em tempos de crise, cabe um destaque para a emergência dos BRICS - China, Rússia, Brasil, Índia, África do Sul. É notório que o núcleo duro dos BRICS está na articulação estratégica China e Rússia, com acordos em longo prazo, a tensionar com a hegemonia estadunidense na civilização do capital. No entanto, para além da afirmação de países emergentes no sistema do capital, os BRICS despontam como a criação de outro polo de poder nos marcos do capitalismo, a confrontar com a hegemonia dos EEUU e Europa Ocidental. Assim, como enfatiza François Houtart (2015), trata-se de um modelo antihegemônico, embora não antisistêmico, no interior da civilização do capital. E, nesta condição, como sustentam Mônica Bruckmann e Theotonio dos Santos (2015), os BRICS encarnam potencialidades de uma aliança de civilizações, no âmbito do Sul, apontando para uma diversidade civilizatória como instrumento fundamental para desenvolver novas formas de coexistência global. É a construção de uma agenda econômica e política, a partir de questões estratégicas: inversões compartilhadas em setores de infraestrutura, energia e telecomunicações; criação de novos mecanismos de cooperação entre mercados de valores, em direção ao estabelecimento de uma plataforma unificada de comércio; criação de instrumentos de financiamentos comuns, como o Banco de Desenvolvimento dos BRICS, com o objetivo de promover financiamento para o desenvolvimento (CARVALHO, 2015d).
Assim, no contexto de reviravoltas geopolíticas deste século XXI, os Estados Unidos são impelidos a redirecionar sua politica internacional, visando, de modo específico, Rússia e China maiores credores de sua impagável dívida externa e polos de disputa de diferentes ordens, com confronto de interesses. Estrategistas chegam a sinalizar para a possibilidade de uma segunda guerra fria (SANTOS, 2014). Nesta geopolítica contemporânea da crise, analistas falam de um sistema multipolar, sustentado em processos civilizatórios que impulsionam uma diversidade de países, de Estados Nacionais, de Movimentos Sociais, em meio a uma pluralidade de culturas e identidades.

No intrincado jogo de xadrez do século XXI, uma peça importante é a América Latina, na sua busca de autonomia política, com a emergência de processos de afirmação dos povos originários como sujeitos coletivos, resgatando, suas raízes civilizatórias, encarnadas em saberes tradicionais, a assumirem visibilidade e reconhecimento sóciopolítico. Especificamente, na primeira década deste século, a América Latina afirma-se, na cena mundial, como espaço de insurgência, referência nos processos contra-hegemônicos, demarcando, assim, um novo ciclo de lutas emancipatórias ${ }^{9}$ (CARVALHO, 2012).

A rigor, a grave crise do neoliberalismo, no contexto latino-americano, entre 1998 e 2003, com o aumento da desigualdade, pobreza e desemprego, a esgarçarem o tecido social, propiciou um novo ciclo de acumulação política de forças progressistas e de esquerda, encarnadas em Movimentos Sociais e Governos democraticamente eleitos, com distintos níveis de tensionamento com os centros de poder hegemônico. É um movimento de virada à esquerda, fundado em experiências insurrecionais e organizativas, abrindo caminho para a onda democrática a varrer a região, com governos progressistas, que derrotaram oligarquias tradicionais, limitaram a influência dos EUA na região, promoveram programas sociais que reduziram a pobreza em seus países. E, esses governos, que marcaram a primeira década do século XXI, viabilizaram, como conquista mais significativa, a volta da esquerda, gerando apreensão e medo nos poderes políticos tradicionais e constituindo uma efetiva via de enfrentamento ao poderio norteamericano (MANTILLLA, 2015). Neste panorama latino-americano, pontilhado por governos de esquerda, criaram-se condições para avanços nos projetos e processos de integração regional, na perspectiva de um modelo de integração soberana, fundado nos princípios da solidariedade e cooperação, com destaque para a Aliança Bolivariana para os Povos da Nossa América (ALBA) e a Unidade de Nações Sul Americanas (UNASUL) (CARVALHO, 2012). 
Nesta segunda década do século XXI, em contexto internacional adverso, com a desaceleração da economia chinesa, a crise parece deslocar-se para a América Latina, verificando-se mudanças nas relações de poder, sinalizando para a tendência de uma guinada à direita. $\mathrm{E}$, determinados fatos $\mathrm{e}$ fenômenos são tomados como indicadores de tal tendência: os chamados golpes institucionais de Estado, em Honduras, já no final da primeira década, mais precisamente, em 2009, e no Paraguai, em 2012; a vitória de Macri, em 2015, na Argentina, governo de direita, de caráter abertamente neoliberal; retrocessos nas eleições regionais mais recentes no Equador e na Bolívia, com a derrota em cidades-chave das forças progressistas; crise na Venezuela, com a morte e ausência da liderança de Hugo Chávez, provocando sérias dificuldades governamentais na gestão do Presidente Nicolás Maduro, somando-se à queda dos preços do petróleo; crise no Brasil, em um cenário de acirramento do neoconservadorismo, com graves adversidades enfrentadas pelo segundo governo Dilma Rousseff, a atingir recordes de impopularidade e a conviver com ameaças de impeachment e ataques permanentes de uma oposição ultraconservadora; moderação da frente ampla no Uruguai, após o fim do período de José Mujica e o retorno de Tabaré Vázquez ao poder; crescente descontentamento de importantes movimentos sociais, em especial, setores-chave dos povos indígenas com as politicas de Evo Morales, na Bolívia, e Rafael Correa, no Equador, a despeito da ampla margem de governabilidade nos dois países.

Este momento histórico impõe uma questão fundante a desafiar analistas e sujeitos políticos, na cena contemporânea: essa tendência de uma guinada à direita, em meio a indicadores de debilidade do projeto político progressista e/ou de esquerda que marcou a região nos primeiros anos do milênio, significa o fim de um ciclo na América Latina? Abrese a polêmica a exigir uma avaliação dos sentidos da chamada virada à esquerda, no contexto das relações de força no continente. Inegavelmente, os governos latino-americanos integrantes deste campo progressista e/ou de esquerda, nos anos 2000 , em suas especificidades de natureza e de perfis, possibilitaram conquistas, nos processos de ampliação do Estado. Encarnaram um acúmulo de forças políticas, constituindo referências na busca de autonomia da America Latina, sobretudo, em relação ao Império Norte Americano e suas tradicionais formas de domínio econômico, político e cultural na região. No entanto, em meio às conquistas, tais governos mostraram zonas cinzentas e limitações. A primeira delas é a promoção de projetos extrativistas, como via de inserção no capitalismo contemporâneo, gerando resistências sociais de grupos atingidos, nos processos de acumulação por espoliação e graves danos ambientais em territórios ecologicamente sensíveis. Desse modo. Configuram- se, nestes governos, econômicas dependentes de commodities, no interior de modelos de ajuste rentista-extrativistas, dependentes do que pode ser designado novo imperialismo chinês. De fato, estes governos progressistas e/ou de esquerda tiveram dificuldades de gerar novas dinâmicas produtivas e inovação em política de circulação, distribuição e consumo que apontassem para um tensionamento com o sistema do capital, em uma perspectiva de um anti-capitalismo possível (MANTILLA, 2015) ${ }^{10}$.

Analistas da cena latino-americana de nossos dias, como Alejandro Mantilla (2015) abrem uma instigante via de interpretação para este momento histórico propondo compreender o fim do ciclo como a interrupção da etapa de ascensão de governos progressistas e reinício de uma etapa que exigirá novas lutas, em um contexto de evidentes antagonismos. Afirma Mantilla (2015) que a consolidação ou não do fim de ciclo progressista na região dependerá das possibilidades organizativas e de ação do movimento popular latino-americano. E mais, "Desta instância também dependerá a correção do rumo programático e político das esquerdas no continente." (MANTILLA, 2015, p. 3).

É, justamente, neste cenário geopolítico multipolar do capitalismo em crise, que se forja a contemporaneidade brasileira nos seus ciclos e crises. Assim, pensar o Brasil, neste início de século, desconectado deste jogo de xadrez do sistema mundo, resulta em uma visão superficial e distorcida, desconsiderando determinações fundantes, que se expressam, de modo particular, nas tessituras da vida social do País. A crise brasileira é a manifestação singular da crise estrutural do capital, com as devidas mediações econômicas, políticas e culturais da formação social brasileira, nos circuitos da História.

\section{A CONTEMPORANEIDADE BRASILEIRA NA CIVILIZAÇÃO DO CAPITAL EM CRISE}

No esforço analítico de circunscrever a contemporaneidade brasileira, partimos de um marco histórico fundante, qual seja: a confluência complexa e contraditória dos processos de democratização e de ajuste estrutural à ordem do capital mundializado, em tempos de financeirização da economia ${ }^{11}$. De fato, nas duas últimas décadas do século $X X$ e primeira do século XXI e metade da segunda, a tessitura da vida brasileira é estruturalmente marcada por dois processos que, a partir de 1990, confluem, de forma contraditória, com distintas perspectivas sócio-políticas, a encarnarem-se nas configurações do Estado e das Políticas Públicas: a democratização, com ápice na década de 1980 , com a promulgação da Constituição Federal de 1988, a ampliar o Estado Brasileiro pela via da Política - a grande Política no dizer gramsciano construindo o Estado Democrático de Direito, com 
afirmação e reconhecimento jurídico-institucional dos Direitos Sociais, como fundamento de Políticas Públicas Ampliadas, de caráter universalizante; a experiência tardia, intensiva e dependente de ajuste ao capitalismo financeirizado, a partir de 1990, submetendo o Estado aos ditames de expansão do capital, na configuração de um Estado Ajustador Estado que ajusta e ajusta-se às imposições dos padrões de acumulação capitalista - a limitar, de diferentes formas, a força da Política,a restringir o domínio da Democracia, desenvolvendo Políticas Públicas Macro Econômicas de Ajuste, a privilegiar superávit primário, equilíbrio da balança comercial, no sentido da rentabilidade do capital financeiro e produzindo, ao mesmo tempo, uma precarização das Políticas Públicas, direcionadas para o atendimento da população brasileira. Concretamente, as políticas de ajuste, em sua ortodoxia, estruturam os interesses do capital, em composições orgânicas e desestruturam a proteção social, desmontando o domínio do público, ao negar e desconsiderar Direitos (CARVALHO, 2015a, 2015c, 2015d).

Em um olhar crítico-reflexivo, nos percursos da vida brasileira nestes últimos vinte e cinco anos, revela-se, com clareza, a dominância dos processos de ajuste, restringindo as potencialidades da democracia, submetida à lógica de expansão do capital. A rigor, tem-se em curso o Brasil do Ajuste, em meio aos tensionamentos das lutas e embates democráticos, com maior ou menor intensidade, em cada conjuntura da inserção brasileira ao capitalismo financeirizado. Desse modo, predomina - Estado Ajustador, com efetiva intervenção nos processos de acumulação e valorização do capital, a gerar formas restritas de inserção das massas pauperizadas via diferentes mecanismos e estratégias de enfrentamento da pobreza. É o neointervencionismo estatal, a configurar-se, de forma efetiva, com distintas inflexões, nos percursos do ajuste brasileiro, nestes vinte e cinco anos.

Assim sendo, uma chave analítica de fundo no desvendamento das tessituras do Brasil Contemporâneo consiste, precisamente, em circunscrever os percursos da experiência brasileira de ajuste na ordem do capitalismo financeirizado, tendo, como fio condutor, o processo de inserção do País no movimento da acumulação do capital em nível mundial (PAULANI, 2012a). Neste sentido, necessário se faz demarcar, para efeito heurístico, uma dupla via de inserção brasileira, organicamente vinculada: a inserção ativa e subordinada na acumulação rentista, constituindo-se o Brasil, no século XXI, uma plataforma emergente de valorização financeira, a garantir ganhos inigualáveis - um dos maiores ganhos do mundo - mediante elevação das taxas de juro, no âmbito de uma política monetária e cambial do ajuste; a inserção internacional periférica e subordinada nos processos de acumulação por espoliação, com base na produção de commodities, com destaque para commodities agrícolas, particularmente soja e suco de laranja e commodities minerais, sobremodo minério de ferro, alumínio e petróleo (CARVALHO, 2014)12. A rigor, ao longo de vinte e cinco anos de ajuste, o Brasil configura uma versão peculiar do padrão de acumulação capitalista dominante no continente latino-americano: o modelo rentistaextrativista, centrado na financeirização dependente e no extrativismo intensivo de riquezas, em uma reedição contemporânea do modelo extrativista primário-exportador (CARVALHO; GUERRA, 2015). Logo, este modelo vigente, de ajuste brasileiro, bem expressa uma dependência redobrada, nos circuitos do capitalismo financeirizado, na instigante síntese de Leda Paulani (2012b).

Adentrando nos interstícios desta experiência brasileira de ajuste ao capitalismo financeirizado, impõe-se demarcar distinções, inflexões no interior do modelo rentista-extrativista, a circunscrever distintos ciclos de ajuste: o primeiro ciclo, na última década do século XX, a adotar, de forma disciplinada, o discurso e a prática neoliberais, no que pode ser denominado ciclo de estabilização da economia, compreendendo os governos Collor e Itamar Franco e, sobremaneira, a era FHC, organicamente vinculada à derrota da inflação e à proclamada conquista da estabilidade, seguindo à agenda do Consenso de Washington; o segundo ciclo de ajuste, já no século XXI, a se consubstanciar no primeiro e em parte do segundo governo Lula, a seguir à risca a política macroeconômica de ajuste, investindo em políticas de enfrentamento à pobreza, a garantir uma inserção social passiva das massas pelo consumo, podendo, assim, ser nomeado de ciclo de consolidação das políticas de ajuste e de reconstituição do mercado interno de consumo de massas; o terceiro ciclo de ajuste, encarnado nos últimos dois anos do segundo governo Lula e no primeiro governo Dilma Rousseff, a efetivar uma inflexão da política econômica, qual seja, mantem o núcleo duro da política de ajuste, a incorporar uma dimensão de desenvolvimento, podendo, pois, ser denominado ciclo de articulação de políticas de ajuste e neodesenvolvimentismo; neste ciclo, especificamente no primeiro governo Dilma Rousseff, verifica-se uma tentativa de afastamento da cartilha ortodoxa do ajuste, com a retomada de dimensões de heterodoxia econômica, escanteada pela lógica do ajuste, tentando, desse modo, uma guinada progressista na orientação da política econômica; por fim, um quarto ciclo que a iniciarse no segundo governo Dilma Rousseff, em meio à grave crise brasileira, implicando em um ajuste à direita, a retomar a ortodoxia das políticas de ajuste, nos marcos da financeirização dependente e dos processos de acumulação por espoliação, a privilegiar os interesses do capital, sem quaisquer limites do que pode ser nomeado de democracia de 
mercado $^{13}$ (CARVALHO; GUERRA, 2015). Nessa retomada da ortodoxia, fragilizam-se as disputas por fundo público, em benefício de políticas direcionadas aos mais pobres para viabilizar, acima de tudo, a rentabilidade do capital financeiro, em suas orgânicas composições. Silvio Caccia Bava (2015b), ao referirse a este ciclo de volta da ortodoxia das políticas de ajuste, proclama, no titulo do Editorial do Le Monde Diplomatique Brasil, de junho de 2015, Saudades de como era antes, significando saudades de como era antes para os mais pobres, em mais de uma década de governos petistas. De fato, o antes de Caccia Bava (2015b) é esse momento histórico, nos ciclos de ajuste, de direcionamento de uma parcelapequena, mas crescente - da riqueza para os mais pobres, em uma perspectiva de proteção social, ainda que restrita! É a Proteção Social Restrita dos governos petistas, nos percursos do ajuste brasileiro!

Cabe um destaque de relevância no desvendamento analítico: o ajuste brasileiro, em suas tessituras desde os anos 1990 até o momento presente - primeiro bimestre de 2016 -, em seus diferentes ciclos - aqui demarcados e nomeados assenta-se em um padrão de políticas públicas assumidas pelo Estado Ajustador: no plano macroeconômico, políticas de ajuste, nos marcos do modelo rentista-extrativista, a atender, fundamentalmente, ao capital, favorecendo os interesses do setor financeiro-um dos mais beneficiados com as políticas de ajuste - em articulação orgânica com segmentos do capital vinculados aos processos de acumulação por espoliação, notadamente o agronegócio. E, ao longo dos percursos de expansão do capital, sem limites e sem formas de regulação democrática, efetiva-se a crescente Mercantilização dos Serviços Públicos, notadamente na Saúde, na Educação, na Previdência, na Segurança Pública, dentre outros campos. De fato, serviços, no âmbito dos direitos sociais e trabalhistas, são transmutados em Mercadorias, sob a égide da lógica do capital, em uma poderosa rede de privatização, com efetivo poder de pressão, via lobbys, no interior dos diferentes poderes constitutivos do Estado Brasileiro Contemporâneo, em especial, no Legislativo e Executivo. E, neste jogo de soma zero, na medida em que se consolida a mercantilização dos Serviços Públicos, efetiva-se um desmonte da proposta de Seguridade Social propugnada no Estado Democrático de Direito e legalmente instituída na Constituição Federal de 1988 - atingindo, violentamente, o Sistema Único de Saúde (SUS), a Educação Pública, a Previdência Social. É a desestruturação da Seguridade Social como conquista democrática, sempre na perspectiva da mercantilização e da rentabilidade do capital que preside os processos de ajuste aos circuitos do capitalismo financeirizado (CARVALHO, 2015a).

Especificamente, no século XXI, mais precisamente na primeira década, no segundo ciclo de ajuste na Era Lula, consolidam-se as políticas brasileiras de ajuste, nos marcos da dependência, na condição do Brasil de plataforma de valorização financeira e de exportador de commodities, nos processos de acumulação por espoliação, em expansão. Verifica-se, então, uma relevante inflexão no processo brasileiro de ajuste ao capitalismo contemporâneo que passa à História como marca de governos petistas: em articulação com políticas públicas privilegiadoras do capital, instaura-se uma perspectiva pontual e restrita de distribuição de renda, encarnada nas chamadas políticas de enfrentamento à pobreza, sem, contudo, alterar, estruturalmente, o histórico padrão de desigualdade social do Brasil. Tais políticas envolvem determinados mecanismos e estratégias: elevação substancial do salário mínimo, com impacto no sistema previdenciário em termos do pagamento dos benefícios; mutações no mundo do trabalho, com a retomada do emprego formal, por um lado, e, por outro, com a ampliação da economia informal, em suas múltiplas capilaridades e na sua extrema diversidade, engendradas pelo próprio crescimento da economia; a bancarização da população de baixa renda, com a política de acesso ao crédito, mediante endividamento, com destaque para os empréstimos consignados; osprogramas de distribuição de renda, sendo emblemático o Bolsa Família, em sua amplitude nacional, com efetivas repercussões no tecido social brasileiro (PAULANI, 2010; CARVALHO; GUERRA, 2015).

Em um contexto internacional favorável, sobremodo, no cenário pós-crise de 2008, o Brasil consegue crescer, chegando a $7 \%$ - índice chinês - com alterações no perfil distributivo do País, com a proclamada emergência de 30 milhões de pessoas que migram dos segmentos miseráveis e empobrecidos para o que se denominou, à época, de uma classe média baixa, gerando, na avaliação de Calixtre (2015), um conflito distributivo ${ }^{14}$. Nesta perspectiva, afirma-se o propalado modelo brasileiro de crescimento com inclusão, característico dos governos petistas nos percursos do ajuste brasileiro e, sobremodo, associado à figura carismática do Presidente Luís Inácio Lula da Silva. À época, proclama-se a performance da economia brasileira, a pairar altaneira em meio ao mundo em crise, falando-se mesmo de uma forma mais criativa de garantir crescimento econômico com inclusão. Em verdade, trata-se de um arranjo de ajuste aos circuitos do capitalismo financeirizado perigoso, arriscado e instável (CARVALHO; GUERRA, 2015). No entanto, é preciso destacar um elemento inovador nos percursos de ajuste brasileiro, com efetivas repercussões na vida social, qual seja, a dupla utilização do Fundo Público pelo Estado Ajustador: o governo utiliza o Fundo Público para beneficiar, prioritariamente, interesses do capital, mas utiliza uma parcela pequena, porém crescente, deste Fundo Público, para desenvolver amplos programas sociais de caráter distributivo que garantem a 
inserção de setores empobrecidos na cidadania do consumo. É o distributivismo sem reformas estruturais, justamente as reformas capazes de atingir e reduzir o histórico padrão de desigualdade que perpassa a vida brasileira (CARVALHO, 2015a).

No final da primeira década dos anos 2000 e limiar da segunda, nos dois últimos anos do segundo mandato do presidente Lula e, sobretudo, no primeiro Governo Dilma Rousseff, mais precisamente, no terceiro ciclo de ajuste, a tentativa é desenvolver um hibrido arranjo de políticas de ajuste e neodesenvolvimentismo. Nesta perspectiva, o primeiro governo Dilma Rousseff tenta afastarse da ortodoxia do modelo de ajuste. Avalia Leda Paulani (2014) que, neste primeiro governo, Dilma Rousseff empreende uma guinada progressista na orientação da política econômica que a faz ser odiada pelo mercado financeiro: começou com uma guinada do Banco Central, baixou os juros, enfrentou corajosamente o lobby financeiro, usando os bancos públicos para reduzir os spreads dos bancos privados, deu força para o PAC e para o Minha Casa, Minha Vida que é um grande pacote de investimentos e tem efeito multiplicador na economia.

Em verdade, no âmbito desta perspectiva híbrida de políticas de ajuste com neodesenvolvimentismo, o Estado Brasileiro lançou mão de instrumentos indutores de um padrão de desenvolvimento para realizar políticas sociais capazes de garantir um mínimo de qualidade de vida para os mais empobrecidos, sendo emblemática a perspectiva do Brasil Sem Miséria.

Uma questão-chave é que as elites financeiras e o capital internacional não podiamaceitar esta perspectiva de ajuste a afastar-se da ortodoxia, com a disputa de fundo público com o rentismo. É importante assinalar que tal posicionamento do capital financeiro, intransigentemente contrário à disputa de fundo público com o rentismo, constitui um componente que está na base do jogo de xadrez da crise brasileira (CARVALHO; GUERRA, 2015).

Ademais, cabe destacar que, não obstante todo o esforço realizado pelo governo para que o setor privado caminhasse na direção da retomada de novos projetos de ampliação da capacidade produtiva do Brasil, a presidenta não consegue envolver, de fato, os setores produtivos na pretendida arrancada desenvolvimentista. Vivencia-se, então, o aparente paradoxo da paralisia dos investimentos.

É importante atentar que o dinamismo da economia na primeira década do século XXI e limiar da segunda, está focado no consumo do mercado interno e não no investimento produtivo. E mais, esse consumo está assentado na expansão do crédito, ou seja, no endividamento dos consumidores, particularmente, provindos dos segmentos mais empobrecidos em ascensão social. E alerta Leda Paulani (2012b, p. 4)
[...] ancorar a dinâmica macroeconômica no consumo e o consumo no crédito é tentar fazer a economia capitalista andar com o motor girando ao contrário.

A rigor, o modelo brasileiro de ajuste, em sua versão peculiar do padrão rentista-extrativista, associado às políticas de enfrentamento à pobreza, com inflexões neodesenvolvimentistas no âmbito da lógica do capital financeirizado, revelou-se estruturalmente instável e inseguro. O crescimento com inclusão não se mostrou sustentável. Assim, em um contexto externo desfavorável, os impasses e dilemas deste modelo brasileiro persistem e agravam-se. De fato, a partir de 2011-2012 e, de modo mais intensivo, em 2013-2014, o governo Dilma Rousseff se vê diante de dificuldades, com progressiva diminuição dos índices de crescimento, elevação dos patamares de inflação, diminuição de superávit primário, déficit na conta corrente. Instaurase, então, uma fase de recessão, delineando a crise brasileira contemporânea, que, de fato, inaugura um novo ciclo, com o esgotamento do padrão econômico e político vigente (CARVALHO; GUERRA, 2015).

Em um contexto de crise brasileira, sistematicamente trabalhada pela midia, Dilma Rousseff, inicia o seu segundo governo, com o que vem sendo denominado de ajuste à direita, significando a retomada da ortodoxia das políticas de ajuste. Neste sentido, é emblemática a figura do Ministro da Fazenda, escolhido no início do seu segundo mandato - Joaquim Levi ${ }^{15}$ - que fala aos mercados, tranquilizando-os sobre os rumos do País, a priorizar a rentabilidade financeira, acima de tudo! Tarso Genro (2015), em matéria na Carta Maior, na segunda quinzena de junho de 2015, denuncia o Fascismo Financeiro, marcante neste período que, se não for brecado, fará desaparecer as próprias liberdades políticas.

Desse modo, no contexto de crises que se superpõe o terrorismo midiático e dos mercados, recessão e manifestações, orquestradas pelas oposições, insatisfação popular, o segundo governo de Dilma Rousseff inicia-se encarnando a exigência de ajustes dentro da ortodoxia rentista, colocando em xeque o padrão de políticas públicas distributivas de inclusão, características dos governos petistas. Ajustar para voltar a crescer parece se a palavra de ordem oficial! O rentismo parece impor ao governo o desmonte dos mecanismos e instrumentos da proteção social restrita, apontando para acirramento de processos de exclusões e desproteções (CARVALHO; GUERRA, 2015).

4 BRASIL DO AJUSTE EM CRISE: pulsações das energias emancipatórias neste contexto de conservadorismo e de privatização da vida brasileira

Na cena contemporânea, a crise brasileira está a nos desafiar a compreendê-la, a decifrar a 
sua natureza, o seu espectro e o próprio horizonte da vida do País, em curto e médio prazos!

Afinal, do que se trata? $O$ que está em jogo, neste intrincado tabuleiro de xadrez, marcado por confrontos, desencontros, recessão, conservadorismos, discursos políticos truncados, falta de alternativas?

Defato, a crise brasileira, cujas manifestações mais evidentes aparecem nos últimos dois anos, a se revelar com dramática intensidade, neste primeiro semestre de 2015, é uma encarnação peculiar da crise do capital que em seus permanentes deslocamentos geográficos, materializa-se na América Latina, e particularmente, no Brasil. As tessituras desta crise estão organicamente vinculadas aos ciclos de ajuste brasileiro, nomeadamente aqueles viabilizados nos doze anos de governos petistas (CARVALHO; GUERRA, 2015).

A nosso ver, múltiplas dimensões de esgotamento parecem se articular, nos campos econômicos, político e cultural, em uma complexa tessitura da crise, circunscrevendo um eixo estrutural e estruturante da contemporaneidade no Brasil: o esgotamento da versão brasileira, do modelo rentista-extrativista, com mecanismos de distribuição de renda. Trata-se do esgotamento de um padrão de inserção do País nos processos mundiais de acumulação, a hibridizar rentismo e extrativismo em composições orgânicas do capital a penalizar distintos segmentos e grupos das classes trabalhadoras. Mais especificamente, é o esgotamento do propalado modelo brasileiro de crescimento com inclusão social, na perspectiva difundida de combinar desenvolvimento com justiça social (CARVALHO; GUERRA, 2015).

Analistas apontam que a grande dificuldade, no âmbito da crise, é definir o futuro, constatandose uma ausência de alternativas tanto do lado do governo e de suas forças aliadas, como das oposições (GRZBOWSKI, 2015; ARANTES, 2015).

Enfim, em termos gramscianos, estamos a viver uma crise de hegemonia, com o vazio que tem se mostrado perigoso e propício a um avanço oportunista de forças políticas conservadoras, respaldadas na mídia dominante, a apostar no pior para ocupar espaços políticos, repondo na agenda política o desmonte de direitos conquistados ao longo da História, sobremodo nos percursos da democratização. Dois casos são emblemáticos: 0 Projeto de Lei n. 4.330, de 26 de outubro de 2004, a radicalizar a possibilidade de terceirização do trabalho; o Projeto de Emenda Constitucional (PEC) n. 171, de 19 de agosto de 1993, que reduz a idade de responsabilidade penal de 18 para 16 anos. São proposições de subtração de direitos, recentemente aprovadas pela Câmara dos Deputados que, cada vez mais, afirma a sua perspectiva eminentemente conservadora e patrimonialista!
Em verdade, nos circuitos da crise, o Estado Ajustador é reafirmado em sua versão mais fiel às prescrições da rentabilidade do capital financeirizado. E este Estado é perpassado fortemente por interesses do capital e pelo conservadorismo. Silvio Caccia Bava, em Editorial no Le Monde Diplomatique de maio de 2015, intitulado Captura do Sistema Política, traça um quadro do que considera o maior problema de nossa democracia que é, justamente, a captura do sistema político pelo poder econômico. Em suas análises, sustenta Caccia Bava (2015a) que o Congresso Nacional de 2015 não está formado por bancadas de partidos políticos e, sim, por bancadas de interesses privados que estão distribuídos por todos os partidos: Bancada Ruralista; Bancada dos Bancos; Bancada dos Frigoríficos; Bancada das Mineradoras; Bancada da Bala; Bancada Evangélica; Bancada da Bebida Alcoólica. Enfim, afirma que Congresso Nacional 2015 é militantemente conservador e reacionário, impondo políticas de restrição de direitos (BAVA, 2015a).

A questão fundamental a avaliar é, justamente, quais as forças sociais operantes na luta por direitos, a tensionar com os interesses do capital neste Brasil do Ajuste em crise. A rigor, em meio aos percursos do ajuste brasileiro à ordem do capital faz-se fundamental avaliar as forças de resistências, encarnadas em Movimentos Sociais, de múltiplos formatos e diferentes naturezas, a tensionarem e/ou enfrentarem interesses do capital, impulsionadores dos processos de ajuste do País ao capitalismo financeirizado. Enfim, em que nível e de que formas, no interior da sociedade civil, forças sociais vinculadas aos interesses das classes trabalhadoras e, particularmente, dos setores populares, ao longo desses vinte e cinco anos de ajuste brasileiro, vem conseguindo se expressar politicamente, com capacidade de interferência na dinâmica do Estado Brasileiro e nas configurações das Políticas Públicas? De fato, impõe-se a análise da Equação Estado/Sociedade na vida brasileira (CARVALHO; GUERRA, 2014)16. É esta uma equação com muitas variáveis e impasses, a desafiar os nossos esquemas analíticos (CARVALHO; GUERRA, 2014; CARVALHO, 2015c).

Em uma avaliação das relações de força, ao longo dos vinte e cinco anos de ajuste, percebese uma diferença qualitativa entre o potencial de resistência e luta das forças vinculados aos interesses dos trabalhadores nos anos 1990 - a tensionar com os governos de Collor de Mello/Itamar Franco e com os governos FHC e, nos anos 2000, no âmbito dos governos petistas (CARVALHO, 2015c). Hoje, em meio a crise brasileira, tendemos a concordar com avaliações políticas que indicam a ausência, na cena pública, de sujeitos coletivos de transformação, a encarnarem movimentos, que, de suas trincheiras, lutem com capacidade de 
apresentar alternativas efetivas de mudanças de rumo do modelo brasileiro. Neste sentido, a garantia de direitos, na perspectiva da afirmação da dialética igualdade/diferença, se faz uma trincheira da luta de classes, como proclama Paulo Arantes (2015). No entanto, precisamos ampliar o nosso olhar no sentido de uma ampliação dos nossos referenciais analíticos, para perceber as energias emancipatórias que pulsam em determinados movimentos que, com suas bandeiras de luta, tensionam o sistema do capital. Cabendo destaque: Movimento dos Sem Teto (MST); Hip-Hop, Movimentos Anárquico Punks; Movimentos Feministas, com destaque para a Marcha Mundial das Mulheres e a Articulação de Mulheres Brasileiras; Movimentos da Juventude Proletária com o Levante Popular (BARROS, 2015). Enfim, é preciso estar atento e vigilante para as energias utópicas que conseguem mover a Política: a grande Política, no sentido gramsciano.

5 A TíTULO DE CONCLUSÃO: e as utopias na contemporaneidade brasileira?

Eis a questão-chave da vida contemporânea, nesta temporalidade histórica da civilização do capital! Fala-se de esgotamento de energias utópicas, como expressão de um discurso neoconservador, em versão século XXI. Comungamos com analistas do pensamento crítico e com reflexões de sujeitos militantes de que a utopia se (re)inventa no tempo presente, em processos de resistência e de lutas.

O exercício da razão crítica, na avaliação política das relações de força, aponta para um cenário de ausência de sujeitos coletivos com efetivo poder de confrontação com o sistema do capital. No entanto, em uma ampliação de olhar, constatamos no cenário mundial, a emergência de forças de tensionamento com a ordem do capitalismo financeirizado. É emblemática a emergência do podemos, como o partido de extrema esquerda mais importante da Espanha a destacar-se no contexto europeu. Em pouco mais de um ano, este partido tem conseguido vitórias políticas! Analistas sinalizam que ante à crise, governos de esquerda ganham espaço na América Latina e na Europa (MORSOLIN, 2015).

Direcionando o olhar para o Brasil, podemos perceber forças em gestação, a tensionarem com o modelo de ajuste e com o próprio Estado Ajustador... São forças que, em suas trincheiras, delineiam espaços de resistência e luta. É deveras significativo o delineamento de um Projeto Popular para o Brasil, assumido como utopia por Movimentos como o Levante Popular da Juventude. Ilena Felipe Barros (2013), em curso de formação para este Movimento - que congrega juventudes que exercem a rebeldia e a indignação - circunscreve como elementos constitutivos deste projeto: dimensão de classe social; dimensão de consciência de classe; dimensão de luta por direitos; dimensão do trabalho de base; dimensão do cuidado, dimensão da transformação social.

Em verdade, assumimos a utopia proclamada por Boaventura de Sousa Santos (2007), intelectual militante do nosso tempo: a (Re) invenção da Emancipação no século XXI.

\section{REFERÊNCIAS}

ALVES, G. A condição de proletariedade na Modernidade Salarial: por uma analítica existencial do proletariado. Revista Pegada, Presidente Prudente, v. 9, n. 2, p. 1-38, dez. 2008. Disponível em:<file:///C:/ Users/Eliana\%20Guerra/Documents/ALBA\%20 2014/A\%20CONDI\%C3\%87\%C3\%83O\%20DE\%20 PROLETARIEDADE.pdf>. Acesso em: 23 fev. 2016.

PL 4330: o tiro de misericórdia na regulação do trabalho brasileiro. Revista Eletrônica da IHU Unisinos, São Leolpodo, ano 15, n. 464, 2015. Entrevista. Não paginado. Disponível em:<http:// www.ihuonline.unisinos.br/index.php? secao $=464>$. Acesso em: 10 maio 2015.

ANISTIA INTERNACIONAL. O custo humano da fortaleza europeia. Rio de Janeiro, 2014. Disponível em:<https://anistia.org.br/direitos-humanos/ publicacoes/violacoes-de-direitos-humanos-contraimigrantes-e-refugiados-nas-fronteiras-da-europa/>. Acesso em: 25 fev. 2016.

ARANTES, P. O capitalismo está morrendo de overdose. Revista Caros Amigos, fev. 2015.

BARROS, I. F. [Comentários críticos na Banca de Qualificação do mestrando de Serviço Social Felipe dos Santos Cabral]. Natal: UFRN, 2015. Dissertação intitulada Ousar, lutar, organizando a juventude pro Projeto Popular: o Levante Popular da Juventude em foco.

Projeto Popular: levante popular da juventude. Rio Grande do Norte, 2013. Mimeo. Curso de Agitação e Propaganda.

BAVA, S. C. A captura do sistema político. Le Monde Diplomatique do Brasil, São Paulo, ano 2, n. 94, maio 2015a. Editorial.

Saudades de como era antes. Le Monde Diplomatique do Brasil, São Paulo ano 2, n. 94, maio 2015b. Editorial.

BELLUZZO, L. G. A crise é chinesa?: vivemos o último, mas não derradeiro, movimento da sinfonia inspirada nos arranjos melódicos dos anos 1980. Carta Capital, São Paulo, set. 2015. Disponível em:<http://www.cartacapital.com.br/revista/866/acrise- e-chinesa-1456.html>. Acesso em: 23 fev. 2016. 
BLOCH, E. Utopie et espérance. Paris: Les Éditions du Cerf, 1974. (Collection Horizon philosophique).

BRUCKMANN, M.; SANTOS, T. dos. Actualidad del espíritu de Bandung: por una agenda estratégica de América Latina. América Latina em Movimiento, Quito, n. 504, año 39, mayo 2015. Disponível em:<www.alainet.org/revista.phtml>. Acesso em: 8 jun. 2015.

CALIXTRE, A. B. América do Sul: uma guinada à direita? Revista Unisino, São Leopoldo, dez. 2015. Entrevista. Disponível em:<http://www.ihu.unisinos. br/entrevistas/549815-america-do-sul-uma-guinadaa-direita-entrevista-especial-com-andre-bojikiancalixtre>. Acesso em: 28 fev. 2016.

CARVALHO, A. M. P. de. Contemporaneidade Brasileira na civilização do capital em crise: configurações do Brasil do Ajuste em uma mirada panorâmica Mesa Serviço Social: Trabalho e Formação profissional no contexto do capitalismo contemporâneo. In: SEMINÁRIO 65 ANOS, 2015, Fortaleza. Anais... Fortaleza: Curso de Serviço Social, 2015a. Mimeo.

Democracia na América Latina no século XXI: lições da história. In: CONGRESSO DE CULTURA E EDUCAÇÃO PARA A INTEGRAÇÃO DA AMÉRICA LATINA, 3., 2012, Curitiba. Anais... Curitiba: CASLA, 2012. Mesa redonda Política, Cidadania e Democracia na América Latina. Mimeo.

Democracia, Estado, Desenvolvimento e Conflitos Sociais: trilha analítica para pensar o Brasil Contemporâneo na Civilização do Capital. In: JORNADA DE CIÊNCIAS SOCIAIS, 3., 2014, São Luís. Conferência de Abertura. São Luís: UEMA, 2014. Mimeo.

Desenvolvimento, Cultura e Identidades nas Américas. In: COLÓQUIO INTERNACIONAL POLÍTICA INDUSTRIAL DE COMÉRCIO EXTERIOR FACE AO DUPLO PROCESSO DE REPRIMARIZAÇÃO/DESINDUSTRIALIZAÇÃ, 2015, Fortaleza. Anais... Fortaleza, 2015b. Mimeo.

. Políticas Públicas no Brasil Contemporâneo: crítica de percursos e discussão de rumos em tempos de crise. In: SEMINÁRIO DO DIA DO ASSISTENTE SOCIAL, 2015, Fortaleza. Anais... Fortaleza: CRESS-CE, 2015c. Mimeo.

Políticas Públicas no Brasil Contemporâneo: interpelações reflexivas. Boletim do Conselho Regional de Serviço Social, Fortaleza, 2015d.

; GUERRA, E. C. Brasil Contemporâneo: a equação Estado/Sociedade em distintos momentos históricos da vida brasileira (1980-2014). In:
SEMINÁRIO DO PROYECTO PAPIIT, 2014, Roma. Anais... Roma, 2014.

O Brasil no século XXI nos circuitos da crise do capital: o modelo brasileiro de ajuste no foco da crítica. Revista de Políticas Públicas, São Luís, v. 19, n. 1, p. 41-60, jan./jun. 2015. Disponível em:<www.revistapoliticaspublicas.ufma.br/site/ download.php?id_publicacao=997>. Acesso em: 1 jan. 2016.

FILGUEIRAS, L.; GONÇALVES, R. A economia política do Governo Lula. São Paulo: Contraponto, 2007.

FIORI, J. L. A nova geopolítica das nações e o lugar da Rússia, China, Índia, Brasil e África do Sul. IKOS: Revista de economia heterodoxa, Rio de Janeiro, n. 8, ano 6, p. 77-106, 2007. Disponível em:<http:// www.revistaoikos.org/seer/index.php/oikos/article/ view/10/6>. Acesso em: 23 fev. 2016.

GENRO, T. Os cidadãos servos e o Congresso do PT. Carta Maior, São Paulo, 2015. Disponível em:<http://cartamaior.com.br/?/Editoria/Politica/ Tarso-Genro-Os-cidadaos-servos-e-o-Congressodo-PT/4/33720>. Acesso em: 20 jun. 2015.

GONÇALVES, R. Crise econômica é reflexo da crise do Estado brasileiro. Revista Unisino, São Leopoldo, ago. 2015. Entrevista. Disponível em:<http://www.ihu.unisinos.br/entrevistas/546174crise- economica-e- reflexo-da- crise-do- estadobrasileiro-entrevista- especial-com- reinaldogoncalves>. Acesso em: 24 fev. 2016.

GRZYBOWSKI, C. Os poderes instituinte e constituinte da sociedade como armas contra crise. Revista Eletrônica da IHU Unisinos, São Leolpodo, mar. 2015. Entrevista concedida a João Vitor dos Santos. Disponível em:<http://www.ihu.unisinos. br/entrevistas/540824-os-poderes-instituinte-econstituinte-da sociedade.como-armas-contracrise-entrevista-especial-com-candido-grzybowski>. Acesso em: 20 abr. 2015.

HOUTART, F. De Bandung a los BRICS: proyectos anti-hegemônicos pero no anti-sistémicos. América Latina em Movimiento, Quito, n. 504, ano 39, p. 27-29, mayo 2015. Disponível em:<www.alainet.org/ revista.phtml>. Acesso em: 8 jun. 2015.

LÖWY, M. Le "principe esperance" d'Ernst Bloch face au "principe responsabilite". Revue Eletronique Hypotheses, Paris, 2013. Disponivel em:<https://f.hypotheses.org/wp-content/blogs. dir/203/files/2013/01/LOWY_Bloch.Jonas_.pdf>. Acesso em: 26 fev. 2006. 
MANTILLA, A. América Latina: fim de ciclo? Revista Eletrônica da IHU Unisinos, São Leolpodo, nov. 2015. Disponível em:<http://www.ihu.unisinos. $\mathrm{br} /$ noticias/549402-america-latina-fim-de-ciclo>. Acesso em: 25 fev. 2016.

MARX, K.; ENGELS, F. Manifesto Comunista. São Paulo: Boitempo, 1998.

MORSOLIN, C. Ante la crisis gobiernos de la izquierda ganan espacio em Latinoamérica y Europa. Adital: notícias de América Latina y Caribe. Entrevista com Juan Carlos Monedero. Junho 2015. Disponível em:<http://site.adital.com.br/site/noticia. php?lang=ES\&cod=85502>. Acesso em: 20 jun. 2015.

NADAL, A. China e a sua primeira crise capitalista. Esquerda.net, Lisboa, jul. 2015. Entrevista. Disponível em:<http://www.esquerda.net/artigo/ china-e- sua-primeira- crise-capitalista/37988>. Acesso em: 23 fev. 2016.

PAULANI, L. M. A dependência redobrada. Le Monde Diplomatique do Brasil, São Paulo, 2012b. Economia.

A inserção da economia brasileira no cenário mundial: uma reflexão sobre a situação atual à luz da História. Boletim de Economia e Política Internacional, n. 10, abr./jun. 2012a.

Capitalismo financeiro, Estado de emergência econômico e hegemonia às avessas no Brasil. In: OLIVEIRA, F. de; BRAGA, R.; RIZEK, C. S. (Orgs.) Hegemonia às avessas: economia, política e cultura na era da servidão financeira. São Paulo: Boitempo, 2010.

Mídia e mercado fazem "terrorismo econômico". Brasil de Fato, São Paulo, nov. 2014. Entrevista concedida a Bruno Pavan. Disponível em:<http://www.brasildefato.com.br/node/30418>. Acesso em: 19 mar. 2015.

SANTOS, B. de S. A gramática do tempo: para uma nova cultura política. São Paulo: Cortez Editora, 2006.

A sociologia das ausências e das emergências. In: _org.). Conhecimento prudente para uma vida decente: um discurso sobre as ciências revisitado. São Paulo: Cortez, 2004.

A Terceira Guerra Mundial. Carta Maior, São Paulo, dez. 2014b. Disponível em:<http:// cartamaior.com.br/?/Coluna/A-Terceira-GuerraMundial-/32494>. Acesso em: 10 mar. 2015.
Renovar a teoria crítica e reinventar a emancipação social. São Paulo: Boitempo, 2007.

VERGOPOULOS, K. Atualização da utopia concreta no Século XXI. In: JORNADA INTERNACIONAL DE POLÍTICAS PÚBLICAS, 7., 2015, São Luís. Anais... São Luís: PPGPP/UFMA, 2015. Conferência de encerramento.

ZIZEK, S. Primeiro como tragédia, depois como farsa. São Paulo: Boitempo, 2011.

\section{NOTAS}

1 O presente artigo integra as reflexões e discussões da mesa temática Experiências, expressões e espaços de utopia: a cena contemporânea brasileira nos circuitos da geopolítica da crise, apresentada na VII JOINPP, com a proposição analítica de adentrar na contemporaneidade brasileira, nos marcos do ajuste ao capitalismo finaceirizado, trabalhando dimensões específicas da vida social, nos territórios urbanos, em meio às desigualdades e violências, nas tramas da pobreza e nas trajetórias das juventudes. Inegavelmente, é este um amplo campo de estudos ousado e interpelador, que nos coloca em face de um dos dilemas centrais do nosso tempo: o repensar a utopia, com os sentidos, que assume, neste jovem século XXI, como nos alerta Kosta Vergopoulos (2015) em sua conferencia de encerramento da VII JOINPP intitulada Atualizacão da utopia concreta no Século XXI. Nesta configuração temática, o texto, ora apresentado, constitui um aporte de fundo, na perspectiva de delinear o Brasil Contemporâneo no cenário da civilização do capital, nesta geopolítica da crise, tentando esboçar tendências e traços de possibilidades utópicas, em meio a um clima de conservadorismo e intolerâncias.

2 Ernest Bloch (1885-1959), filósofo, musicista e grande pensador do século XX. Em sua trajetória colocou-se contra o totalitarismo nazista, chegando a perder sua nacionalidade Alemã e exilar-se, em 1933, na Suíça e mais tarde (1938), nos Estados Unidos. No pós-guerra. O seu livro Le Principe Espérance constitui uma de suas principais e mais importantes elaborações teóricas, integrando o campo do pensamento emancipatório (LOWY, 2013). Obra produzida durante seu exílio nos Estados Unidos, entre 1938 e 1947. Em Espírito da Utopia (1974), desenvolve a ideia de utopia como consciência antecipatória. O Non-encore-être (em francês) e o ainda não (tradução para o português) figura com um de seus conceitos de extrema fecundidade para pensar a utopia, mesmo em tempos sombrios. O ainda não como o possível, o que pode se revelar à consciência antecipatória. O ainda não, como possibilidade a emergir, envolve um componente de incerteza, ou mais precisamente, uma possibilidade incerta. Nessa perspectiva, o ainda não pode ser a possibilidade da utopia. Para Michel Löwy (2013), a filosofia de Ernest Bloch é um convite a centrar-se em uma das categorias mais descuidada pela ciência moderna: a da possibilidade. Para Bloch (1974) o ainda não consciente do ser humano indica o devir da história, o que não ainda se manifestou no mundo. Para o autor, o mundo humano é pleno de disposições a alguma coisa, de tendência a alguma coisa, de latência; qualquer coisa reporta-se à concretização de uma intenção utópica, tomando utopia como consciência antecipadora (LÖWY, 2013).

3 Em verdade, trata-se do pleno exercício do que Boaventura de Souza Santos $(2004,2006)$ circunscreve como sociologia das emergências, a encarnar uma nova racionalidade, no sentido de delinear alternativas 
possíveis no futuro, que já despontam como sinais ou pistas credíveis. É o possível que já vem se constituindo, germinando como alternativa histórica.

4 Em estreita vinculação com a busca de traços de possibilidade, inclusive, como condição para antever sinalizações utópicas, impõe-se a exigência do que Boaventura de Sousa Santos $(2004,2006)$ define como sociologia das ausências, no esforço de expandir o presente, conferindo visibilidade ao que é socialmente produzido como não existente. E, desse modo, rompe-se com as distintas estratégias do pensamento dominante, ao apresentar o parcial, o pontual, o seletivo como o único, o universal, a restringir a integralidade do real ao que é posto e imposto como visível e credível, a sustentar relações de poder e domínio.

5 A crise estrutural do capital, que se revela com dramática intensidade em 2008-2009 e continua em curso com diferentes desdobramentos, tem sido objeto de análises sistemáticas em duas mesas coordenadas apresentadas na V e VI JOINPP. Senão vejamos: em 2011, a mesa intitulada Reconfigurações do Estado e políticas públicas no contexto da crise estrutural do capital, composta pelos pesquisadores Alba Carvalho, Alcides Gussi, Carlos Américo Moreira, Agamenon Almeida, Jawdat Abu-El- Haj; em 2013, a mesa denominada Expressões contemporâneas da crise na civilização do capital: lutas, resistências sócio-políticas e movimentos transnacionais, constituída pelos pesquisadores Alba Carvalho, Eliana Guerra, Rejane Vasconcelos e Ricardo Kaminski. Nas discussões empreendidas nas duas mesas buscou-se trabalhar distintas configurações da crise, chegando a trabalhar movimentos de resistência no mundo ocidental e no América Latina.

6 Depois do fim da União Soviética e da Guerra Fria e no auge da globalização financeira, o mundo experimentou, na década de 1990, a possibilidade real de um império global: o Projeto Imperial Americano. A rigor, os Estados Unidos, nos governos de Bush pai e, depois, nos dois mandatos de Clinton, mantêm um forte ativismo militar, com numerosas intervenções, ao mesmo tempo em que sustenta a intransigente defesa do liberalismo econômico, com pressões concretas e efetivas para obter a abertura e desregulação de todos os mercados nacionais. É o auge da ideologia globalitária. Os governantes estadunidenses estavam convencidos de que o novo século deveria ser o século americano. Em verdade, esse projeto imperial dos Estados Unidos, em meio a essa ideologia da globalização, ficou um tanto encoberto, ganhando visibilidade no início do século XXI, a partir dos atentados de 11 de setembro de 2001 , quando os Estados Unidos, então, mudam a retórica da sua politica externa, evidenciando seu poderio imperial, ao defender o direito unilateral de fazer intervenções militares preventivas, em nome da guerra global ao terrorismo (FIORI, 2007).

7 Slavoj Zizek (2011), encarnando uma inspiração marxiana, na sua instigante obra Primeiro como tragédia, depois como farsa, publicada em português, em 2011, pela Boitempo, destaca como dois eventos que marcaram o começo e o fim da primeira década do século XXI: os ataques de 11 de setembro e a crise financeira de 2008, argumentando, como a partir deles, os EUA mudam o seu discurso e a sua intervenção no interior da civilização do capital.

8 Segundo a Anistia Internacional milhares de migrantes e refugiados tentam chegar à Europa. Alguns, movidos pela necessidade de escapar da miséria, outros, fugindo da violência e da perseguição. Com jornadas permeadas de perigos, tentam adentrar nas fronteiras dos países da União Europeia em busca de segurança e meios de vida para, logo, concluírem tratar-se de uma luta vã. Estima-se que pelo menos 23 mil pessoas perderam suas vidas tentando chegar à
Europa, desde 2000, tornando o drama dos refugiados uma das facetas mais perversas da questão social, na contemporaneidade (ANISTIA INTERNACIONAL, 2014).

De fato, numa visão panorâmica dos séculos $X I X$ e $X X$, a América Latina, na Histórica posição de dependência no contexto geopolítico, vivenciou diferentes ciclos de lutas emancipatórias, de caráter regional, com potencial de confronto com a ordem colonialista e imperialista, que vão desde as lutas pela independência no século XIX, passando pelos movimentos nacionalistas no século $X X$, com destaque para a revolução mexicana entre 1910-1920 e para a luta anti-imperialista de Augusto Sandino, na Nicarágua entre 1929-1934, até a onda emancipatória inaugurada pela revolução cubana de 1959, com grande impacto político-ideológico sobre a região, parecendo gerar condições para realizar a tarefa proposta por Mariatégui, no início do século XX de pensar um socialismo indo-americano. Ao longo das quatro últimas décadas do século $X X$ e, hoje, no século $X X I$, cuba é uma referência nas lutas emancipatórias, encarnando uma possibilidade de autonomia e resistência, em meio à ofensiva, aos embates norteamericanos. No século XXI, a América Latina deflagrou um novo ciclo de Lutas Emancipatórias, encarnado em movimentos sociais que conseguem, pela via democrática, constituir governos progressistas e de esquerda, com uma efetiva heterogeneidade de perspectivas, mas que convergem em uma redefinição estratégica de inserção da América Latina na geopolítica mundial (CARVALHO, 2012).

10 Em artigo no Colômbia Info, publicado por Outras Palavras, em 23 de novembro de 2015, Alejandro Mantilla desenvolve uma lúcida avaliação sobre esta questão de fim de ciclo na América Latina, defendendo que este momento talvez obrigue a esquerda a uma saudável reinvenção.

11 Noesforço de desvendamento doBrasil Contemporâneo, em suas tessituras históricas, consideramos, como uma fecunda chave analítica, esta confluência contraditória dos processos de democratização e de ajuste, a encarnar-se em duas configurações estatais que marcam a vida brasileira: o Estado Democrático de Direito e o Estado Ajustador. Ao longo dos últimos vinte e cinco anos, sustentamos a tese de uma dominância do neointervencionismo do Estado Ajustador, em meio aos tensionamentos do Estado Democrático, submetido às exigências de expansão do capital.

12 Ao (re)assumir, em tempos contemporâneos, a posição de produtor de commodities, com base no extrativismo, o Brasil vincula-se comercialmente com a China, uma das principais nações importadoras das riquezas minerais e agrícolas brasileiras. Deste modo, nos percursos das experiências de ajuste, o País assume uma posição de dependência em relação ao chamado Império Chinês, a mercê dos circuitos de expansão e de desaceleração da China, como potência capitalista mundial.

Noesforço de desvendamento do Brasil Contemporâneo, em suas tessituras históricas, consideramos, como uma fecunda chave analítica, esta confluência contraditória dos processos de democratização e de ajuste, a encarnar-se em duas configurações estatais que marcam a vida brasileira: o Estado Democrático de Direito e o Estado Ajustador. Ao longo dos últimos vinte e cinco anos, sustentamos a tese de uma dominância do neointervencionismo do Estado Ajustador, em meio 
aos tensionamentos do Estado Democrático, submetido às exigências de expansão do capital.

Cabe considerar o recente acordo bilateral BrasilChina, em que, de forma patética, configura-se a dependência brasileira: por um lado, chineses oferecem financiamento para que compremos seus bens e serviços e; por outro, o Brasil exportará minério de ferro, soja e petróleo e facilitará privatizações na logística que interessa às empresas chineses importadoras de commodities do País. Neste sentido, afirma Reinaldo Gonçalves que "[...] o Brasil redescobre, em pleno século XXI, sua vocação para colônia." (GONÇALVES, 2015, p. 8)

13 Uma análise da inserção do Brasil no capitalismo financeirizado, com a configuração de ciclos de ajuste nos últimos vinte e cinco anos, encontra-se no artigo de Carvalho e Guerra (2015), pesquisa realizada em 23 de fevereiro de 2016.

14 Segundo André Bojikian Calixtre (2015) destaca que a ascensão das novas classes emergentes se dá relacionada a fatores econômicos, sem uma identificação política com o projeto que as fizeram emergir. Alerta, então, que a ideologia sobre a qual se sustenta esse processo de ascensão funda-se no individualismo, retomando o mito do pensamento dominante de que o individuo consegue mudar de vida apenas por meio de seu próprio esforço, descolado de qualquer perspectiva coletiva de organização.

Esta conceituação de Modelo Liberal Periférico foi pioneiramente concebida por Luiz Filgueiras, professor da Universidade Federal da Bahia (UFBA). Em obra de 2013, intitulada Desenvolvimento às Avessas, Reinaldo Gonçalves assume este conceito como uma das referências básicas para a análise da economia brasileira e de suas perspectivas. Na caracterização de Filgeurias e Gonçalves (2007), O MLP tem três conjuntos de características marcantes: liberalização, privatização e desregulação; subordinação e vulnerabilidade externa estrutural; dominação do capital financeiro. O modelo é liberal porque é estruturado a partir da liberalização das relações econômicas internacionais nas esferas comercial, produtiva, tecnológica e monetáriofinanceira; da implementação de reformas no âmbito do Estado, em especial na área da previdência social e da privatização de empresas estatais e de um processo de desregulação do mercado de trabalho. O modelo é periférico porque consiste em uma forma específica de realização da doutrina liberal e da sua política econômica em um país que ocupa posição subalterna no sistema econômico internacional.

15 Joaquim Lévy permanece quase um ano à frente do Ministério da Fazenda (janeiro/dezembro de 2015) na tentativa de implementar o modelo ortodoxo de ajuste, visando o crescimento econômico a qualquer custo. Foi substituído, em 18 de dezembro de 2015, pelo então ministro do planejamento Nelson Barbosa, cuja missão é reestabelecer o reequilíbrio da dívida pública, sobretudo no que diz respeito ao nível da meta de superávit primário (economia para pagar os juros da dívida).

\section{Alba Maria Pinho de Carvalho}

Assistente Social

Doutora em Sociologia pela Universidade Federal do

Ceará (UFC)

Professora Associada da UFC

E-mail: albapcarvalho@gmail.com

albapcarvalho@gmail.com.br
Eliana Costa Guerra

Assistente Social

Doutora em Sociologia pela Universidade de Paris VIII

Professora Associada da Universidade Federal do Rio

Grande do Norte (UFRN)

E-mail: elianacostaguerra@hotmail.com

Universidade Federal do Ceará - UFC

Av. da Universidade, 2853 - Benfica, Fortaleza/CE CEP: $60020-181$

Universidade Federal do Rio Grande do Norte - UFRN Campus Universitário Lagoa Nova, Natal/RN CEP 59078-970 